\title{
THE EFFECTS OF MEPROBAMATE AND PENTOBARBITONE SODIUM ON SLEEP AND MOTILITY DURING SLEEP: A CONTROLLED TRIAL WITH PSYCHIATRIC PATIENTS
}

BY

\author{
J. M. HINTON and E. MARLEY
}

From the Professorial Unit, Maudsley Hospital, London S.E.5

Meprobamate (2-methyl-2-n-propyl-1, 3-propanediol dicarbamate) was synthesized by Ludwig and Piech (1951). It is an interneuronal blocking agent capable of producing muscular relaxation without affecting respiration or other vital activities (Berger, 1954). The drug produces restful sleep and generalized muscular relaxation (Borrus, 1955). It was decided to test its effect, compared with that of a placebo and pentobarbitone sodium, on motility measured on a bed providing quantified estimates of movement during sleep or recumbency.

\section{Method}

Eleven male patients aged 22 to 70 years, suffering from hyposomnia of a degree to require a night hypnotic, were studied. They slept in a ward of 10 moderately disturbed psychiatric patients. Of the 11 , eight were depressed, two were schizophrenic, and one was a chronic alcoholic withdrawn from alcohol for four weeks. The trial was of the self-controlled, double-blind variety. Each patient was in the trial for 18 days, the drugs being given in random order at 9.30 p.m. For the first nine days (Series 1) the patient received on three nights each placebo alternating with meprobamate at two dose levels (400 and $800 \mathrm{mg}$.). For the second nine days (Series 2) the effect of $800 \mathrm{mg}$. meprobamate was compared with that of a conventional hypnotic $(200 \mathrm{mg}$. pentobarbitone sodium) and placebo. Meprobamate and placebo were in identical tablet form and the pentobarbitone ("nembutal") in neutral-coloured capsules. The drugs were crushed and given in fluid to the patient. No additional treatment or medication was provided during the trial.

As in the method for validating the bed (Cox and Marley, 1959) the patient's motility scores were recorded hourly from the Veeder-Root counter during the period 10 p.m. to 6 a.m. by one nurse, an independent rating (as in the previous paper) of the patient's sleep being given by another. Eight patients completed a questionnaire (see previous paper) each morning relating to their night's sleep, the other three subjects being unable to comply satisfactorily on account of their mental state.

The results were dealt with by analysis of variance. A one-tail test of significance was employed if the placebo scores were to be compared with a drug score, and a two-tail test of significance if the two drug scores were to be compared.

\section{Results}

The mean and standard error of the mean scores for all results are shown in Table $I$.

Comparison of Effects of Placebo, Meprobamate, and Pentobarbitone Sodium on Motility.-The total motility scores between 10 p.m. and 6 a.m. for Series 1 and 2 were subjected to analysis of variance. For Series 1, the variance ratio between drugs $(\mathrm{F}=5.76, \mathrm{P}<0.01)$ proving significant, the differences between mean motility scores were tested. Only $800 \mathrm{mg}$. significantly, reduced movement (Table II). For Series 2 , the variance ratio between drugs $(F=4.39, P<0.05)$ was significant, so the differences between mean motility scores for the drugs were examined. Both $800 \mathrm{mg}$. meprobamate and $200 \mathrm{mg}$. pentobarbitone sodium significantly reduced movement as compared with placebo (Table II).

Time of Onset of Action of Drugs.-The mean motility scores at 11 p.m., 12 p.m., 1 a.m., and 2 a.m. were subjected to analysis of variance to ascertain the earliest moment the effect of the drug became significant. For both series this was at 12 p.m. The significant differences between the 12 p.m. mean motility scores was due in Series 1 to the effect of $800 \mathrm{mg}$. meprobamate $(\mathrm{t}=2 \cdot 19$, $P<0.02)$ and in Series 2 to the significant difference between the action of placebo and $200 \mathrm{mg}$. pentobarbitone sodium $(t=2.6, P<0.01)$. A significant effect of $800 \mathrm{mg}$. meprobamate was not evident until 1 a.m. in Series 2.

Nurses' and Patients' Ratings of Motility Scores.There was a significant correlation in Series 1 between the nurses' ratings and the total night motility scores $(r=+0.47, P<0.01)$ but not between the patients' rating and the total motility scores $(r=+0 \cdot 22$, $P>0.05$ ). In Series 2 , there was a significant correlation between both the nurses' rating and total night 
TABLE I

MEAN AND STANDARD ERROR OF MEAN FOR MOTILITY SCORES, NURSES', AND PATIENTS' RATINGS DERIVED FROM PATIENTS RECEIVING PLACEBO, MEPROBAMATE, AND PENTOBARBITONE SODIUM

\begin{tabular}{|c|c|c|c|c|c|c|c|c|c|c|c|}
\hline \multirow{3}{*}{ Scores or Ratings } & \multirow{3}{*}{$\begin{array}{l}\text { No. of } \\
\text { Patients }\end{array}$} & \multirow{3}{*}{$\begin{array}{l}\text { Indices } \\
\text { (Units) }\end{array}$} & \multicolumn{9}{|c|}{ Series 1} \\
\hline & & & \multicolumn{3}{|c|}{ Placebo } & \multicolumn{3}{|c|}{$400 \mathrm{mg}$. Meprobamate } & \multicolumn{3}{|c|}{$800 \mathrm{mg}$. Meprobamate } \\
\hline & & & Night 1 & Night 2 & Night 3 & Night 1 & Night 2 & Night 3 & Night 1 & Night 2 & Night 3 \\
\hline $\begin{array}{l}\text { Total motility scores } \\
\text { (bed) }\end{array}$ & 11 & $\begin{array}{l}\text { Mean } \\
\text { S.E. of Mean }\end{array}$ & $\begin{array}{l}77 \cdot 1 \\
19 \cdot 64\end{array}$ & $\begin{array}{l}80 \cdot 1 \\
20 \cdot 09\end{array}$ & $\begin{array}{l}67 \cdot 5 \\
13 \cdot 82\end{array}$ & $\begin{array}{l}69 \cdot 3 \\
18 \cdot 94\end{array}$ & $\begin{array}{l}70 \cdot 8 \\
18 \cdot 64\end{array}$ & $\begin{array}{l}62 \cdot 9 \\
16 \cdot 25\end{array}$ & $\begin{array}{c}40 \cdot 3 \\
8 \cdot 18\end{array}$ & $\begin{array}{l}54 \cdot 4 \\
14 \cdot 43\end{array}$ & $\begin{array}{l}49 \cdot 1 \\
12 \cdot 89\end{array}$ \\
\hline Nurses' total ratings & 11 & $\begin{array}{l}\text { Mean } \\
\text { S.E. of Mean }\end{array}$ & $\begin{array}{c}13 \cdot 5 \\
0.89\end{array}$ & $\begin{array}{c}12 \cdot 6 \\
0 \cdot 75\end{array}$ & $\begin{array}{c}10 \cdot 5 \\
0 \cdot 78\end{array}$ & $\begin{array}{c}10.4 \\
0.63\end{array}$ & $\begin{array}{c}10 \cdot 1 \\
0.64\end{array}$ & $\begin{array}{l}9 \cdot 9 \\
0.52\end{array}$ & $\begin{array}{l}9 \cdot 9 \\
0.72\end{array}$ & $\begin{array}{c}10 \cdot 3 \\
0 \cdot 39\end{array}$ & $\begin{array}{l}9 \cdot 8 \\
0 \cdot 56\end{array}$ \\
\hline Patients' total ratings & 8 & $\begin{array}{l}\text { Mean } \\
\text { S.E. of Mean }\end{array}$ & $\begin{array}{c}13 \cdot 6 \\
0.98\end{array}$ & $\begin{array}{c}13 \cdot 8 \\
0 \cdot 25\end{array}$ & $\begin{array}{c}13 \cdot 6 \\
0.55\end{array}$ & $\begin{array}{c}13 \cdot 8 \\
0 \cdot 83\end{array}$ & $\begin{array}{c}12 \cdot 5 \\
0.66\end{array}$ & $\begin{array}{c}11 \cdot 8 \\
0.75\end{array}$ & $\begin{array}{l}12 \cdot 0 \\
0.69\end{array}$ & $\begin{array}{c}11 \cdot 1 \\
0.97\end{array}$ & $\begin{array}{r}11 \cdot 5 \\
1 \cdot 09\end{array}$ \\
\hline \multirow{3}{*}{ Scores or Ratings } & \multirow{3}{*}{$\begin{array}{l}\text { No. of } \\
\text { Patients }\end{array}$} & \multirow{3}{*}{$\begin{array}{l}\text { Indices } \\
\text { (Units) }\end{array}$} & \multicolumn{9}{|c|}{ Series 2} \\
\hline & & & \multicolumn{3}{|c|}{ Placebo } & \multicolumn{3}{|c|}{$\begin{array}{l}200 \mathrm{mg} \text {. Pentobarbitone } \\
\text { Sodium }\end{array}$} & \multicolumn{3}{|c|}{$800 \mathrm{mg}$. Meprobamate } \\
\hline & & & Night 1 & Night 2 & Night 3 & Night 1 & Night 2 & Night 3 & Night 1 & Night 2 & Night 3 \\
\hline $\begin{array}{l}\text { Total motility scores } \\
\text { (bed) }\end{array}$ & 11 & $\begin{array}{l}\text { Mean } \\
\text { S.E. of Mean }\end{array}$ & $\begin{array}{l}65 \cdot 6 \\
12 \cdot 39\end{array}$ & $\begin{array}{l}62 \cdot 5 \\
14 \cdot 00\end{array}$ & $\begin{array}{l}67 \cdot 2 \\
12 \cdot 21\end{array}$ & $\begin{array}{c}29 \cdot 7 \\
8.01\end{array}$ & $\begin{array}{c}42 \cdot 6 \\
7 \cdot 19\end{array}$ & $\begin{array}{c}44 \cdot 6 \\
8 \cdot 97\end{array}$ & $\begin{array}{c}40 \cdot 1 \\
9 \cdot 67\end{array}$ & $\begin{array}{l}63 \cdot 1 \\
11 \cdot 53\end{array}$ & $\begin{array}{l}48 \cdot 1 \\
8 \cdot 01\end{array}$ \\
\hline Nurses' total ratings & 11 & $\begin{array}{l}\text { Mean } \\
\text { S.E. of Mean }\end{array}$ & $\begin{array}{c}11 \cdot 1 \\
0.93\end{array}$ & $\begin{array}{c}10 \cdot 9 \\
0 \cdot 73\end{array}$ & $\begin{array}{c}11 \cdot 8 \\
0.85\end{array}$ & $\begin{array}{l}9 \cdot 0 \\
0 \cdot 37\end{array}$ & $\begin{array}{l}9 \cdot 5 \\
0.20\end{array}$ & $\begin{array}{l}9 \cdot 6 \\
0 \cdot 44\end{array}$ & $\begin{array}{l}9 \cdot 3 \\
0.55\end{array}$ & $\begin{array}{c}10 \cdot 3 \\
0.61\end{array}$ & $\begin{array}{l}9 \cdot 6 \\
0 \cdot 47\end{array}$ \\
\hline Patients' total ratings & 8 & $\begin{array}{l}\text { Mean } \\
\text { S.E. of Mean }\end{array}$ & $\begin{array}{c}11.9 \\
0.34\end{array}$ & $\begin{array}{c}13 \cdot 1 \\
0 \cdot 70\end{array}$ & $\begin{array}{c}13.6 \\
0.74\end{array}$ & $\begin{array}{c}10 \cdot 6 \\
0.72\end{array}$ & $\begin{array}{c}11 \cdot 0 \\
0.70\end{array}$ & $\begin{array}{c}11 \cdot 1 \\
1.06\end{array}$ & $\begin{array}{c}10 \cdot 6 \\
1 \cdot 14\end{array}$ & $\begin{array}{c}12 \cdot 1 \\
1 \cdot 00\end{array}$ & $\begin{array}{c}11.6 \\
0.94\end{array}$ \\
\hline
\end{tabular}

TABLE II

SYNOPSIS OF FINDINGS FOR DRUG TRIAL

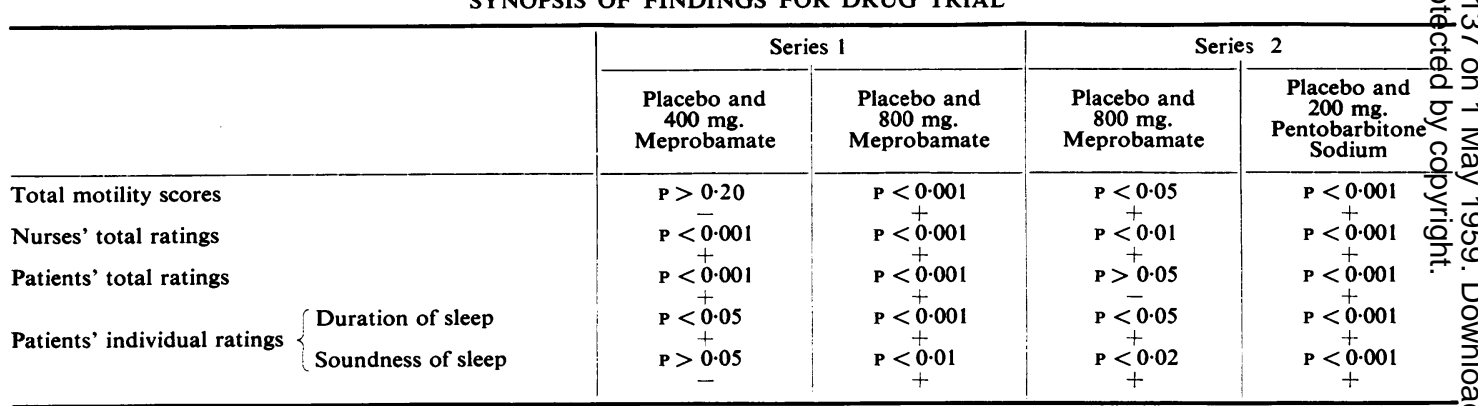

$+=$ significant difference batween mean scores for placebo and drug; $-=$ no significant difference between mean scores for placebo and $\overparen{D}$ drug.

motility scores $(\mathrm{r}=+0.45, \mathrm{P}<0.01)$ and between the patients' rating and total motility scores $(r=+0 \cdot 41$, $\mathbf{P}<0.01$ ).

Analysis of Nurses' Ratings.-As the variance ratio between drugs for Series $1(\mathrm{~F}=12.95, \mathrm{P}<0.001)$ was significant, the mean ratings for the drugs were compared. From the nurses' ratings, it appeared that both 400 and $800 \mathrm{mg}$. meprobamate significantly reduced restlessnes; (Table II). For Series 2 , as the variance ratio between drugs was significant $(F=4.91, P<0.05)$, the mean ratings were compared. From the nurses' ratings both $800 \mathrm{mg}$. meprobamate and $200 \mathrm{mg}$. pentobarbitone sodium significantly reduced restlessness (Table II).

Analysis of Patients' Rating.- - The patients' total rating for their own sleep were subjected to analysis of variance. For Series 1 , as the variance ratio between drugs $(\mathrm{F}=12.95, \mathrm{P}<0.001)$ was significant, the mean ratings were tested. From the patients' ratings, both 400 and $800 \mathrm{mg}$. meprobamate significantly improved sleep (Table II). For Series 2, the variance ratio between drugs $(\mathrm{F}=10 \cdot 16, \mathrm{P}<0.001)$ ? was significant. In this instance, $200 \mathrm{mg}$. pentobarbitone sodium but not $800 \mathrm{mg}$. meprobamate was deemed to have improved sleep significantly.

The totals for the patients' ratings were also split into the individual scores for each of the items ons the questionnaire, and then subjected to analysis of $D$ variance. In Series 1 , the patients stated that they? slept longer both with 400 and $800 \mathrm{mg}$. meprobamaten as compared with placebo (question 2 on the questionnaire) and that sleep was sounder (question 0 3 ) with the $800 \mathrm{mg}$. does as compared with placebow 
FIG. 1.-Mean motility scores at 11 and 12 p.m. and at 1,2 , and 6 a.m. for 11 . patients. (Series 1: bo; $\bigcirc-\square=$ $400 \mathrm{mg}$. meprobamate; $=800 \mathrm{mg}$. meprobamate. Series 2: bamate. Series 2: $\square$ bo; $\square=$ place800 mg. meprobamate; $Q-200 \mathrm{mg}$. pentobarbitone sodium.

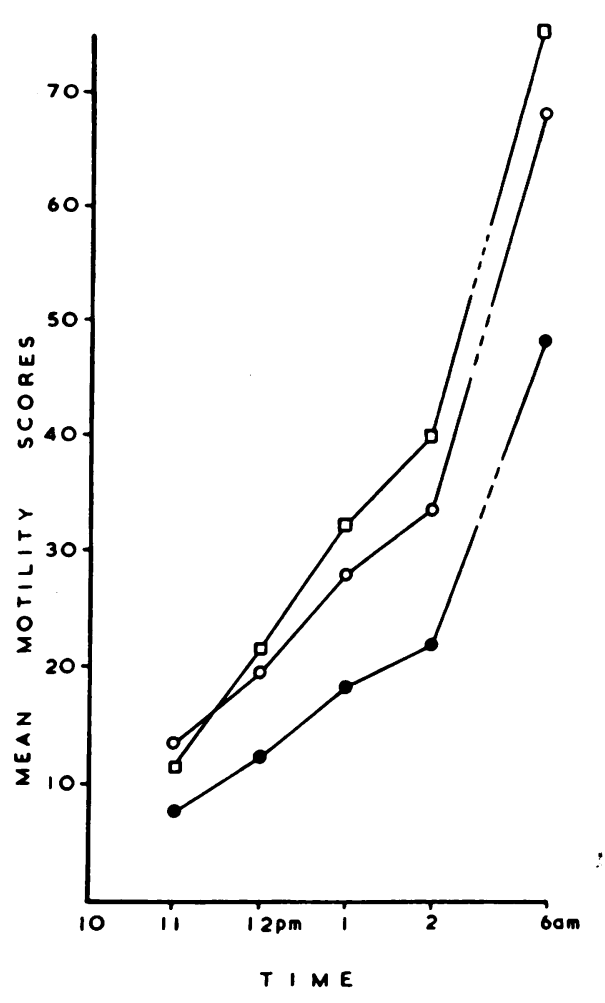

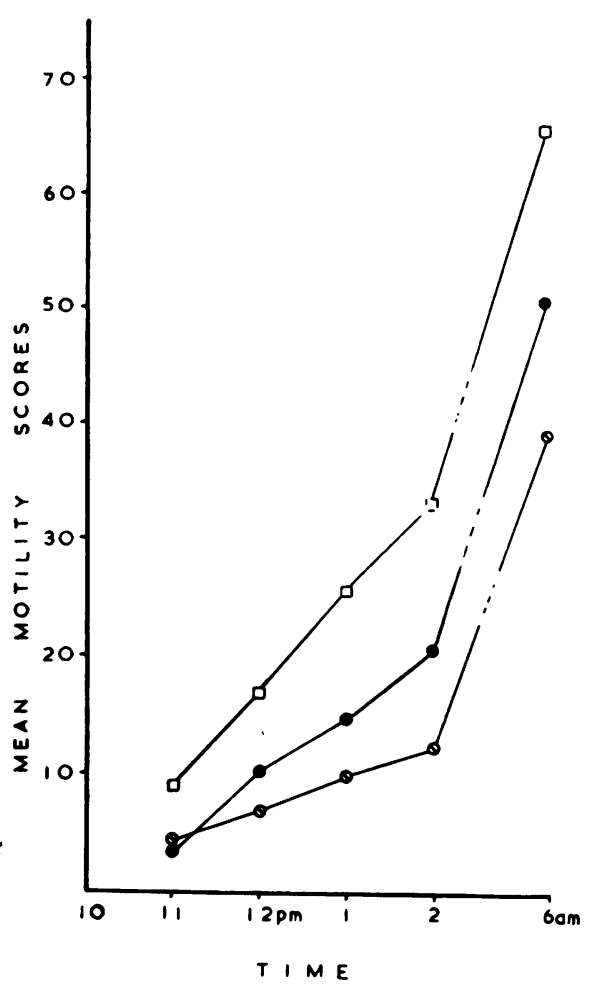

(Table II). For Series 2, patients stated that they slept longer after $200 \mathrm{mg}$. pentobarbitone sodium and $800 \mathrm{mg}$. meprobamate as compared with placebo (question 2), sleep also being sounder (question 3) with these two than with placebo (Table II).

\section{Discussion}

The perfect solution to the problem of measuring depth of sleep remains elusive, and although observations by nurses of the wide-awake or snoring patient are reliable, intervening sleep levels are difficult to determine. Techniques such as shining a light on the patient (Straus, Eisenberg, and Gennis, 1955) have disadvantages, while subjective ratings by the patient may or may not agree with the nurses' evaluation of his sleep (Hare, 1955; Imboden and Lasagna, 1956). In the group of patients we studied, a subjective appraisal alone might have been misleading, for the patients with more severe mental illness were unable to complete the sleep questionnaire. Least weight should be attached to data derived from the questionnaire, as Glaser (1953 1954) and Glaser and Whittow (1953) have shown that repeated completion of questionnaires may diminish the number of responses scored on them giving a false impression in such a case of habituation to the drug. Moreover, in the previous investigation, no correlation was found between the motility scores and the patients' own estimate of sleep (Cox and Marley, 1959).

The objective findings in Series 1 of the drug trial are that $800 \mathrm{mg}$. but not $400 \mathrm{mg}$. meprobamate significantly reduces motility during sleep or recumbency. The subjective findings, on the other hand (nurses' and patients' ratings), suggest that meprobamate at both dose levels is superior to placebo in reducing restlessness and as a hypnotic. Lasagna (1956) noted that of various agents for promoting sleep in chronically ill patients, $400 \mathrm{mg}$. meprobamate was almost as effective as $800 \mathrm{mg}$. of the drug.

In Series 2, the objective findings are that both $200 \mathrm{mg}$. pentobarbitone sodium and $800 \mathrm{mg}$. meprobamate have a definite depressant action on motility, pentobarbitone being superior to meprobamate. The first part of the subjective results (nurses' ratings) are in agreement. However, from the patients' total ratings, pentobarbitone sodium but not $800 \mathrm{mg}$. meprobamate appeared to have 
significant action, although paradoxically analysis of the patients' ratings for individual items on the questionnaire suggests that both drugs are superior to placebo in enhancing duration and soundness of sleep. Lasagna demonstrated that either $400 \mathrm{mg}$. or $800 \mathrm{mg}$. meprobamate was as effective as $100 \mathrm{mg}$. or $200 \mathrm{mg}$. phenobarbitone as a hypnotic, but less effective than either $100 \mathrm{mg}$. or $200 \mathrm{mg}$. quinalbarbitone sodium.

In both series, no significant effect of the drug on motility was detected until 150 minutes (12 p.m.) after administration, that for Series 1 being due to $800 \mathrm{mg}$. meprobamate and for Series 2 attributable to pentobarbitone sodium.

Inasmuch that motility during sleep and depth of sleep are at least partially correlated (and in this investigation there was a significant correlation between motility scores and the nurses' rating in both Series and between motility scores and patients' ratings of sleep in Series 2) the results are consistent with the notion that $800 \mathrm{mg}$. meprobamate possesses weak hypnotic action and reduces restlessness during sleep, although in both respects it is much less effective than $200 \mathrm{mg}$. pentobarbitone sodium. The smaller dose (400 mg.) of meprobamate seems also to possess a mild hypnotic effect but had no significant action on restlessness during sleep. Our results were obtained from patients with severe sleep disturbance, and it may be that both $400 \mathrm{mg}$. and $800 \mathrm{mg}$. meprobamate would exert a more pronounced hypnotic effect in subjects with milder insomnia.

\section{Summary}

Eleven psychiatric patients with marked insomnia were prescribed in random order $400 \mathrm{mg}$., $800 \mathrm{mg}$. meprobamate, and placebo (Series 1), and $200 \mathrm{mg}$. pentobarbitone sodium, $800 \mathrm{mg}$. meprobamate, and placebo (Series 2).

Measurements of motility during sleep were obtained from an electronic recording unit attached to the bed. The patients' sleep was rated also by the nurses and the patients themselves.

Meprobamate, $800 \mathrm{mg}$., but not $400 \mathrm{mg}$., signi ficantly reduced motility scores in Series 1 . In Series 2 , both $200 \mathrm{mg}$. pentobarbitone sodium and $800^{\circ}$ mg. meprobamate significantly diminished restless 20 ness during sleep.

From the nurses' ratings, $200 \mathrm{mg}$. pentobarbiton sodium and $400 \mathrm{mg}$. and $800 \mathrm{mg}$. meprobamate exerted a significant hypnotic action as compared: with placebo.

As judged by the patients' total ratings, 400 mgo and $800 \mathrm{mg}$. meprobamate improved sleep in Serieso 1 but only pentobarbitone in Series 2 . Analysis o $\bar{n}$. individual items from the sleep questionnaire indi $\mathbb{\Omega}$ cated that all drugs used prolonged sleep as compareo with placebo, but that sleep was only sounder after? $800 \mathrm{mg}$. meprobamate or $200 \mathrm{mg}$. pentobarbitone sodium.

It is contended that both $400 \mathrm{mg}$. and $800 \mathrm{mg} \stackrel{\omega}{\omega}$ meprobamate possess weak hypnotic activity, tha $\overline{\mathrm{B}}$ $800 \mathrm{mg}$. reduces restlessness, but that in both respects. $200 \mathrm{mg}$. pentobarbitone sodium is superior.

We take pleasure in thanking Dr. D. L. Davies for suggesting the investigation and for his interest encouragement throughout. We would also like to than $\mathrm{k}$ Dr. A. E. Maxwell for invaluable statistical advice, nursing staff of Ward 4, in particular Sister H. Hypesand Mr. D. Hodge, Mr. W. Brookes, the pharmacist, fol his assistance, Mr. D. A. Green for photographing 贯送 stencil, and also Lederle Laboratories Division tor supplying " miltown" tablets and the placebo.

\section{REFERENCES}

Berger, F. M. (1954). J. Pharmacol., 112413.

Borrus, J. C. (1955). J. Amer. med. Ass., 1571596.

Cox, G. H., and Marley, E. (1959). J. Neurol. Neurosurg. Psychiat. 22. 57.

Glaser, E. M. (1953). Brit. J. Pharmacol., 8, 187.

(1954). Clin. Sci., 13, 199

C. 122, 43P.

Hare, E. H. (1955). Brit. J. prev. soc. Med., 9, 140.

Hare, E. H. (1955). Brit. J. prev. Soc. Med., 9, 140.
Imboden, J., and Lasagna, L. (1956). Bull. Johns Hopk. Hosp., 99, 910
Lasagna, L. (1956). J. chron. Dis., 3, 122.

Ludwig, B. J., and Piech, E. C. (1951). J. Amer. chem. Soc., 73, 5779Straus, B., Eisenberg, J., and Gennis, J. (1955). Ann. intern. Med., 42. 